\title{
Familial atrioventricular septal defect: possible genetic mechanisms
}

\author{
Anil Kumar, Charles A Williams, Benjamin E Victorica
}

Division of Cardiology

A Kumar

B E Victorica

Division of Genetics

C A Williams

Department of

Pediatrics, University

of Florida College of

Medicine, Gainesville, Florida, USA

Correspondence to: Anil Kumar, Division of Pediatric Cardiology, Box 100296, JHMHC, Gainesville, Florida 32610-0296, USA.

Accepted for publication 23 August 1993

\begin{abstract}
Background-Most non-chromosomal congenital heart defects are thought to be caused by the interaction of genetic factors involving multiple genes and environmental factors. Families that have several affected members have been reported, however, which suggests that a single autosomal dominant or recessive gene may cause the cardiac defects. A family in which atrioventricular septal defect seemed to be a single gene disorder is reported.

Observations-A family in which the mother and her two daughters from different fathers had atrioventricular septal defect not associated with trisomy 21 is reported.

Conclusions-This family raises the possibility that cytoplasmic or mitochondrial inheritance may be involved in the causation of atrioventricular septal defects. The available data from pedigrees from other cases of familial atrioventricular septal defect do not support this genetic mechanism, but suggest that
\end{abstract}

there is a subgroup without trisomy 21 that has a single gene disorder.

(Br Heart $\mathcal{f} 1994 ; 71: 79-81)$

Most congenital heart defects occur as isolated malformations, not associated with chromosomal disorders or malformation syndromes. Multifactorial inheritance has generally been accepted as the genetic mechanism causing these isolated malformations. In this model, multiple genes interact with environmental factors to cause the defect in the cardiac phenotype. Environmental factors might include exogenous medications, chemicals, or intrinsic factors such as blood flow through the embryonic heart and the mechanical effects of muscle contraction. Typically risk of recurrence for this type of inheritance is low, usually less than $5 \% .{ }^{1}$ Occasional families stand out, however, with much higher recurrence and have been the subject of many reports. Their pedigrees have suggested an autosomal dominant or recessive pattern of inheritance. Recently, sex influenced or maternal factors have been found to affect the risk of recurrence in congenital heart disease. ${ }^{2}$

We report a family in which the mother and her two children, with different fathers, had an atrioventricular septal defect not associated with trisomy 21 . We review other reported familial cases of anomalies within the spectrum of endocardial cushion defect without trisomy 21 to try to identify a subgroup with a monogenic trait.

\section{Patients and methods}

The figure shows the pedigree. The mother was diagnosed to have congenital heart disease at eight years of age. The defect was surgically repaired at another institution when she was 12. She presented to our institution when she was 17 and was diagnosed by selective cineangiography to have a "gooseneck deformity" of the left ventricular outflow tract and mitral regurgitation secondary to a residual cleft in the mitral valve. An electrocardiogram and vectorcardiogram showed a frontal plane QRS axis of $-40^{\circ}$ and a counterclockwise QRS vector loop. The findings were compatible with her anatomical diagnosis of primum atrial septal defect. She remained hemodynamically compensated and subsequently had three pregnancies resulting in two live births and a spontaneous abortion.

The first daughter was diagnosed to have congestive heart failure at three months of 
Summary of reported pedigrees with atrioventricular septal defects

\begin{tabular}{|c|c|c|c|}
\hline Reference & $\begin{array}{l}\text { Affected } \\
\text { individuals (n) }\end{array}$ & $\begin{array}{l}\text { Affected } \\
\text { generations (n) }\end{array}$ & Mode of transmission \\
\hline Our pedigree & 3 & 2 & $\begin{array}{l}\text { Mother to daughters from different } \\
\text { fathers }\end{array}$ \\
\hline O'Nuallain $e t a l^{5}$ & 6 & 3 & $\begin{array}{l}\text { Transmission from mother and } \\
\text { father }^{\star}\end{array}$ \\
\hline Cousineau $e t a l^{6}$ & 12 & 4 & $\begin{array}{l}\text { Pedigree not } \\
\text { provided } t\end{array}$ \\
\hline Emanuel $e t a l^{7}$ & $\begin{array}{l}2 \\
2\end{array}$ & $\begin{array}{l}2 \\
2\end{array}$ & $\begin{array}{l}\text { Mother to offspring } \\
\text { Mother to offspring }\end{array}$ \\
\hline Marino and Corno ${ }^{8}$ & 2 & $\begin{array}{l}2 \\
2\end{array}$ & $\begin{array}{l}\text { Father to daughter } \\
\text { Father to son }\end{array}$ \\
\hline $\begin{array}{l}\text { Tennant et } a l^{9} \\
\text { Nora }^{10} \\
\text { Yao et al } \\
\text { Disegni } \text { et } a l^{12}\end{array}$ & $\begin{array}{l}3 \\
4 \\
4 \\
2 \\
3\end{array}$ & $\begin{array}{l}2 \\
1 \\
1 \\
1 \\
1\end{array}$ & $\begin{array}{l}\text { Father to offspring } \\
\text { All affected were siblings } \\
\text { All affected were siblings } \\
\text { All affected were siblings } \\
\text { All affected were siblings }\end{array}$ \\
\hline
\end{tabular}

*One family member had "canal" ventricular septal defect.

tAnatomical details not provided; includes some cases with isolated cleft mitral valve.

₹ wo other siblings had isolated left axis deviation. age. An electrocardiogram and vectorcardiogram showed a frontal plane QRS axis of $-45^{\circ}$ and a counterclockwise QRS vector loop. An echocardiogram showed a complete atrioventricular septal defect. Cardiac catheterisation and selective cineangiocardiography at six months confirmed the presence of an atrioventricular septal defect, with a large atrial and a small ventricular component. The defect was surgically repaired at eight months, with confirmation of the anatomical diagnosis. Subsequently, she underwent mitral valve replacement twice, firstly for residual severe mitral regurgitation and secondly for stenosis of the prosthetic valve. She is now 8.5 years old and is doing well since the last operation at three years of age.

The second daughter, from a different father, was diagnosed to have a similar heart defect when five days old. An electrocardiogram and vectorcardiogram showed a frontal plane QRS axis of $-90^{\circ}$, and a counterclockwise QRS vector loop. An echocardiogram showed complete atrioventricular septal defect with small ventricular and large atrial septal defects. Subsequent cardiac catheterisation with selective cineangiocardiography and direct inspection at surgery confirmed the anatomical defect. She is now 6.5 years old and is doing well since the surgical repair at six months. A chromosomal study was normal.

None of these patients had features suggestive of Down's syndrome. There was no history of Down's syndrome in any of the members of the extended family. There was no history of congenital heart disease in any other members of the extended family although they were not specifically examined for it.

\section{Discussion}

Atrioventricular septal defects comprise a spectrum of anatomical defects including complete atrioventricular canal, primum atrial septal defect, and, rarely, a "canal type" inlet ventricular septal defect associated with a tri-leaflet left atrioventricular valve. ${ }^{3}$ Genetically, such defects can be associated with trisomy 21 or other chromosomal defects. Although partial forms of atrioventricular septal defect are more common when the chromosomes are normal, ${ }^{4}$ embryologically and pathologically these groups are similar. Most cases of atrioventricular septal defect are non-familial including those not associated with trisomy 21 . The family reported here is consistent with an autosomal dominant type of inheritance with maternal transmission. As the pedigree is small, other modes such as multifactorial or cytoplasmic (mitochondrial) inheritance cannot be ruled out. A three generation family with atrioventricular septal defect without Down's syndrome with paternal and maternal transmission to offspring has been previously reported and was more typical of an autosomal dominant trait. ${ }^{5}$ Reference is made to a family with atrioventricular septal defect, with 12 affected relatives in four generations but the pedigree is not provided. ${ }^{6}$ Smaller families with vertical transmission have been described and referred to by others (table)..$^{7-9}$ Several affected siblings in one family have also been reported, ${ }^{10-12}$ which is suggestive of autosomal recessive inheritance. As an isolated cleft in the anterior mitral valve leaflet is not usually indicative of an atrioventricular septal defect, ${ }^{3}$ two reported families have been excluded from the list in the table. ${ }^{12}$ In these families, after excluding the cases with an isolated cleft in the mitral valve, recurrence of an atrioventricular septal defect was not evident. As most pedigrees are small and severity of the cardiac disease affects survival and reproductive capacity, a convincing pattern of inheritance may be absent. This may be the reason why in our review, we found so few pedigrees with atrioventricular septal defect occurring in three generations or more. These pedigrees indicate a monogenic subgroup of atrioventricular septal defects, not associated with trisomy 21 . The locus of the gene involved has not been identified, but no linkage has been found to chromosome 21 . $^{\circ}$ Further linkage analysis done on large pedigrees could show the locus of the gene.

In the past, the occurrence of most familial cases of congenital heart defects has been explained by a multifactorial (polygenic) threshold model. These particular families were thought to have a higher genetic burden and thereby could reach the threshold more frequently than the families with isolated cases. ${ }^{10}$ Although multiple genes for risk cannot be disproved, families like those summarised in the table raise the possibility of a single gene defect. In the polygenic model the risk of recurrence in a sibling or offspring of an affected person should be the same and is about equal to the square root of the incidence of the defect in the population. Sanchez-Cascos calculated the risk in first degree relatives to be $1.8 \%$ based on an incidence in the population of atrioventricular septal defect of $0.036 \%$, but actual recurrence in that series was $8 \cdot 7 \% .{ }^{13}$ Based on the available data Nora and Nora suggested a risk of recurrence in siblings of patients with 
atrioventricular septal defect to be $2.9 \%$, rather close to the theoretical risk of recurrence. The risk was much higher for the offspring if the mother had an atrioventricular septal defect $(14 \%)$ than if the father had the same defect $(1 \%) .{ }^{1}$ In the polygenic model, a higher recurrence is expected in relatives of the less frequently affected sex. The sex ratio for atrioventricular septal defect is 1.1 males: 1 female, but the ratio is not high enough to explain the noticeable maternal effect. This led to the suggestion that mitochondrial or cytoplasmic inheritance may be involved in congenital heart disease including atrioventricular septal defect. ${ }^{2}$

In cytoplasmic inheritance the mother transmits the mitochondrial DNA to the offspring in addition to the nuclear DNA. Therefore, if the defect involves mitochondrial DNA, the mother may transmit abnormal mitochondria (as well as normal mitochondria) to all or most of her offspring, whereas the father does not. In the case of atrioventricular septal defect, only one study has shown the importance of maternal effect in its recurrence. ${ }^{7}$ In this study, 19 mothers with an endocardial cushion defect gave birth to 36 infants (sex not specified), five of whom had a congenital heart defect. Two of these infants (one male and one female) had an atrioventricular septal defect, whereas none of the 16 infants had an atrioventricular septal defect when the father was affected. Marino and Corno studied 172 patients with atrioventricular septal defects. Only two of these had a parent with the same lesion and both were fathers. ${ }^{8}$ Taking together the other families with paternal transmission, ${ }^{59}$ the theory of mitochondrial inheritance for most familial cases of atrioventricular septal defect becomes unlikely. In our review of familial cases of atrioventricular septal defect, we did not encounter any family of three or two generations that was strongly suggestive of a mitochondrial inheritance pattern. This would consist of several affected female and male siblings in which only the affected females and not affected males would transmit to the next generation. Families like the one in our report are consistent with this inheritance but not strongly suggestive of it. Moreover the human mitochondrial genome and many of its disease producing mutations have been characterised and sequenced. Mitochondrial DNA has been shown to code for 13 different enzymes of the oxidative phosphorylation system. The clinical phenotype of known defects has involved progressive multisystem degeneration. Leber's hereditary optic neuropathy), rather than having caused congenital malformations. ${ }^{14}$

In conclusion, the genetic cause of atrioventricular septal defect seems to be heterogeneous. Those cases not associated with trisomy 21 are mostly polygenic, but a small proportion of cases suggest a single gene defect. Based on analysis of pedigrees and reported familial cases, there is no strong evidence for cytoplasmic inheritance in familial atrioventricular septal defect.

1 Nora JJ, Nora AH. Update on counseling the family with a first-degree relative with a congenital heart defect. $A m$ a first-degree relative with a
7 Med Genet 1988;29:137-42.

2 Nora J, Nora AH. Maternal transmission of congenital heart diseases: new recurrence risk figures and the questions of cytoplasmic inheritance and vulnerability to tions of cytoplasmic inheritance and vvin
teratogens. Am $\mathcal{F}$ Cardiol 1987;59:459-63.

3 Anderson RH, McCartney FJ, Shinebourne EA, Tynan M, eds. Pediatric cardiology. Edinburgh: Churchill Livingstone, 1987:571-613.

4 Carmi R, Boughman JA, Ferencz C. Endocardial cushion defect: further studies of "isolated" versus "syndromic" occurrence. Am $\mathcal{F}$ Med Genet 1992;43:569-75.

5 O'Nuallain S, Hall JG, Stamm SJ. Autosomal dominan inheritance of endocardial cushion defect. Birth Defects 1977;13:143-7.

6 Cousineau AJ, Sheffield VC, Burns TL, Pierpont ME, Lauer RM. Familial endocardial cushion defects: exclusion from chromosome 21 using short tandem repeat DNA polymorphisms [abstract]. Am $f$ Cardiol 1992; 70:563.

7 Emanuel R, Somerville J, Inns A, Withers R. Evidence of congenital heart disease in the offspring of parents of congenital heart disease in the offspring of pa

8 Marino B, Corno A. Parental transmission of congenital heart disease [letter]. Am $\mathcal{F}$ Cardiol 1988;63:262.

9 Tennant SN, Hammon Jr JW, Bender Jr HW, Graham Tennant SN, Hammon Jr JW, Bender Jr HW, Graham
TP, Primm RK. Familial clustering of atrioventricular TP, Primm RK. Familial clustering of at

10 Nora J. Etiological factors in congenital heart diseases. Nora JJ. Etiological factors in congenital
Pediatr Clin North Am 1971;18:1059-74.

11 Yao J, Thompson MW, Trusler GA, Trimble AS Familial atrial septal defect of the primum type. Can Med Assoc F 1968;98:218-9.

12 Disegni E, Pierpont MEM, Bass JL, Kaplinsky E. Twodimensional echocardiography in detection of endocardial cushion defect in families. Am $\mathcal{F}$ Cardiol 1985;55 1649-52.

13 Sanchez-Cascos A. The recurrence risk in congenital heart disease. Eur $\mathcal{F}$ Cardiol 1978;7:197-210.

14 Clarke LA. Mitochondrial disorders in pediatrics: clinical biochemical and genetic implications. Pediatr Clin North Am 1992;39:319-48. 